\title{
Seismic response analysis of continuous rigid frame bridge considering canyon topography effects under incident SV waves*
}

\author{
Guoliang Zhou ${ }^{1}$ Xiaojun $\mathrm{Li}^{1, \star}$ and Xingjun $\mathrm{Qi}^{2}$ \\ ${ }^{1}$ Institute of Engineering Mechanics, China Earthquake Administration, Harbin 150080, China \\ ${ }^{2}$ School of Civil Engineering, Shandong Jianzhu University, Ji' nan 250101, China
}

\begin{abstract}
To evaluate the importance of the canyon topography effects on large structures, based on a rigid frame bridge across a 137-m-deep and 600-m-wide canyon, the seismic response of the canyon site is analyzed using a two-dimensional finite element model under different seismic SV waves with the assumptions of vertical incidence and oblique incidence to obtain the ground motions, which are used as the excitation input on the pier foundations of the bridge with improved large mass method. The results indicate that canyon topography has significant influences on the ground motions in terms of incident angle. The peak ground acceleration values vary greatly from the bottom of the canyon to the upper corners. Under vertical incident SV waves, at the upper corners of canyon the peak ground accelerations greatly increase; whereas the peak ground accelerations diminish at the bottom corners of canyon. Under oblique incident SV waves, the shaking of the canyon slope perpendicular to the incidence direction is much more severe than that of the opposite side of canyon. And the ground surface has been characterized by larger deformations in the case of oblique incident waves. It is also concluded that the low piers and frame of the continuous rigid frame bridge are more sensitive to the multi-support seismic excitations than the flexible high piers. The canyon topography as well as the oblique incidence of the waves brings the continuous rigid frame bridge severe responses, which should be taken into account in bridge design.
\end{abstract}

Key words: rigid frame bridge; canyon topography effect; multi-support excitation; improved large-mass method; seismic response

CLC number: P315.9 Document code: A

\section{Introduction}

It has been known that the ground motions vary during earthquakes. The variations of ground motions could be classified into traveling wave effect, attenuation effect, loss of coherency effect and local site effect (Kiureghan, 1992). As an important influential factor of site effects, the surface topography has been proved to greatly affect the scattering of seismic waves (Hu and Sun, 1981; Akira and Kasaburo, 1983; Zhao and Valliappan, 1993; Huang and Chiu, 1995). On the whole, the amplitude of vibration greatly increases on the towering mountains and narrow ridges, whereas the ground motions decrease in the canyon, as observed in both re-

\footnotetext{
* Received 20 October 2009; accepted in revised form 4 December 2009; published 10 February 2010.

* Corresponding author. e-mail: beerli@vip.sina.com

(c) The Seismological Society of China and Springer-Verlag Berlin Heidelberg 2010
}

cords from past earthquakes and numerical simulations (Li and Zhao, 2004; Che and Luo, 2008; Lee et al, 2009).

Induced by the topographic irregularity, the wave propagation, reflections and refractions become quite complex. The propagation of seismic waves on canyon site distinctly differs from that on flat surface. The distribution characteristics of ground motions are influenced by small-scale topographic features, which cause non-uniform ground motions. So, the extended structures, such as long-span bridges, are influenced significantly by the non-uniform ground motions considering the canyon topography effects (Sextos et al, 2003).

With rapid development of traffic infrastructures in China, great achievements have been made in bridge engineering. The long-span continuous rigid frame bridges with high piers play a very important role for their eximious capabilities. In China, tens of continuous rigid frame bridges across canyons (as shown in Table 1) have been in service recently (Zhou, 2004). 
Table 1 Representative rigid fame bridges with super high piers in China

\begin{tabular}{cccc||cccc}
\hline Name of bridge & H or R & Location & Height of piers $/ \mathrm{m}$ & Name of bridge & H or R & Location & Height of piers $/ \mathrm{m}$ \\
\hline Yuanjiang & $\mathrm{H}$ & Yunnan & 123 & Taizaogou & $\mathrm{H}$ & Shaanxi & 123.5 \\
Huatupo & $\mathrm{R}$ & Guizhou & 110 & Longtanhe & $\mathrm{H}$ & Hubei & 178 \\
Lizigou & $\mathrm{R}$ & Guizhou & 107 & Weijiazhou & $\mathrm{H}$ & Hubei & 114.2 \\
Qingshuigou & $\mathrm{R}$ & Guizhou & 100 & Mashuihe & H & Hubei & 143.2 \\
Nanpanjiang & $\mathrm{R}$ & Guizhou & 100 & Dukouhe & $\mathrm{R}$ & Hubei & 128 \\
Luohe & $\mathrm{H}$ & Shaanxi & 143.5 & Mashuihe & $\mathrm{R}$ & Hubei & 108 \\
\hline
\end{tabular}

Note: $\mathrm{H}$ denotes highway and $\mathrm{R}$ railway.

Figure 1 shows Yuanjiang bridge built in 2003 and Niulanjiang bridge built in 2005, from which it can be seen that the complex canyon topography makes the piers differ greatly in their heights. The different characteristics between super high-pier bridges and ordinary bridges can be described as: (1) the high-pier bridges with very heavy superstructures exhibit large flexibility and small damping; (2) the lateral stiffness of piers with different height varies greatly, which leads to distinct dynamic characteristics of the piers; (3) geometric nonlinearity with large displacement in super high piers occurs under earthquakes, which induces buckling damage with an increasing probability; (4) the canyon site is characterized by complex geology and terrain, and the input ground motions of piers are quite different (Huang and Chiu, 1995; Lee et al, 2009). It is necessary to study the canyon topography effects on extended bridges, which should be analyzed under non-uniform excitations.
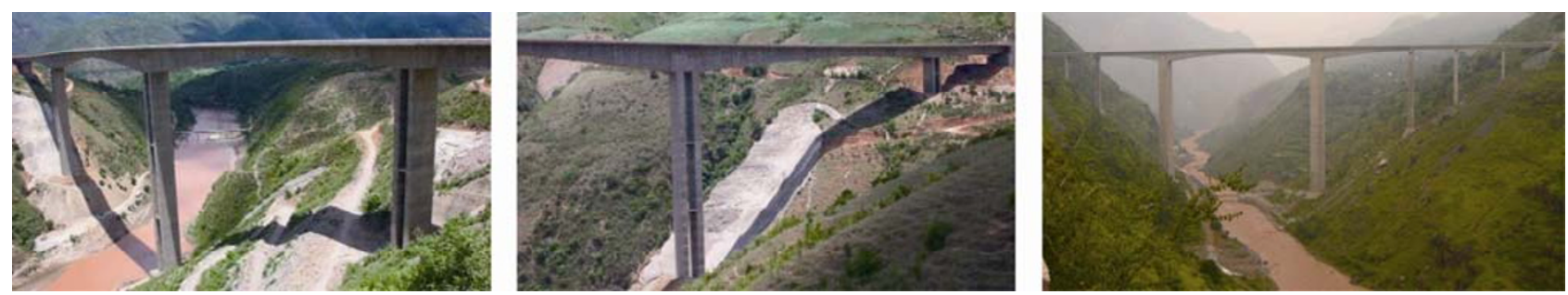

Figure 1 Typical canyon topography and rigid frame bridges.

\section{Local canyon topography and bridge}

As an example, the rigid frame bridge and canyon site are shown in Figure 2. The canyon has a width of $600 \mathrm{~m}$ and a depth of $137 \mathrm{~m}$ with the assumption of homogeneity in geology. The shear wave velocity $v_{\mathrm{S}}$ is $1.0 \mathrm{~km} / \mathrm{s}$, and the $\mathrm{P}$ wave velocity $v_{\mathrm{P}}$ is $1.8 \mathrm{~km} / \mathrm{s}$. The bridge consists of five spans with a total length of $600 \mathrm{~m}$, and is supported on rectangular hollow piers of different heights that vary from $55 \mathrm{~m}$ to $137 \mathrm{~m}$. The deck and piers have a rectangular box section as shown in Figure 3. The incident waves including Elcentro wave, San Fernando wave and Parkfield wave, of which the peak ground accelerations were all adjusted to $200 \mathrm{~cm} / \mathrm{s}^{2}$, are shown in Figure 4 as well as the corresponding response spectra. Two analysis cases are assumed as follows. Case 2 is vertical incidence and case 3 is oblique incidence with an incident angle of $30^{\circ}$.

The two-dimensional finite element model of the canyon site is formed, and the considered area for analysis of the site is $2600 \mathrm{~m}$ wide and $500 \mathrm{~m}$ deep with

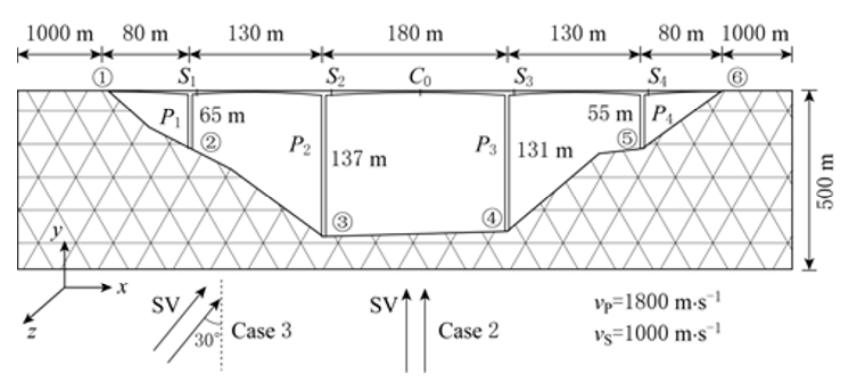

Figure 2 Model of canyon topography and continuous rigid frame bridge. $S_{1}, S_{2}, C_{0}, S_{3}$ and $S_{4}$ denote key locations in the bridge frame; $P_{1}, P_{2}, P_{3}$ and $P_{4}$ denote the four piers of the bridge; and symbols (1), (2), , , (6) denote the six key locations of the canyon site.

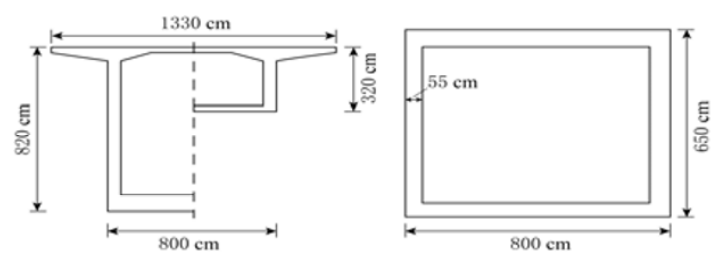

Figure 3 The sections of frame and piers. 

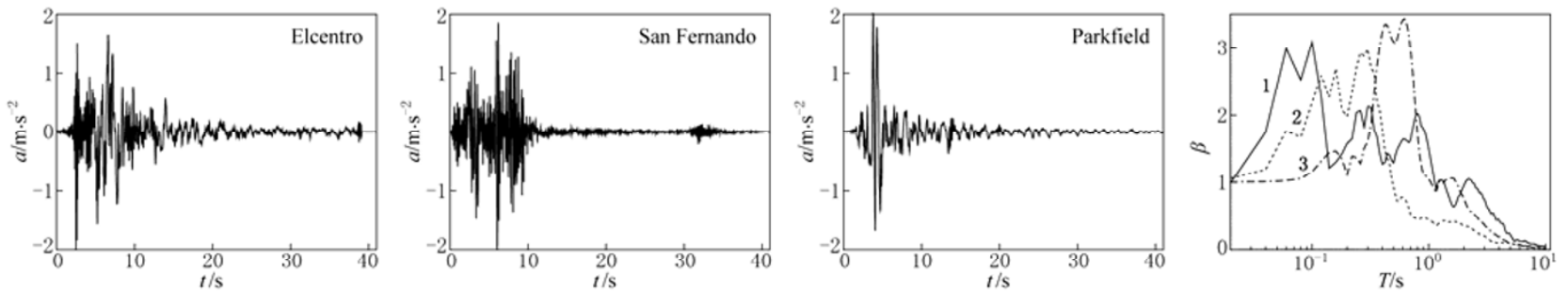

Figure 4 Incident waves and corresponding $\beta$ spectra. Curves 1, 2, 3 denote amplification coefficient $(\beta)$ spectra of Elcentro, San Fernando and Parkfield waves respectively.

the element mesh size of $5 \mathrm{~m}$. The left, right and bottom boundary of the site finite element model is assumed to be the second-order artificial transmitting boundary (Liao, 1996).

The results including peak ground acceleration (PGA), peak ground displacement (PGD), PGA ampli- fication coefficient $\beta$ and the maximum displacements relative to those of the point (3) $\left(D_{\mathrm{r}, \mathrm{max}}\right)$ under incident waves are presented in Tables 2-4.

The results in Tables 2-4 indicate that in the case 2, the peak ground acceleration decreases gradually along the slope direction from the upper corners to the bottom

Table 2 Ground motions under Elcentro wave

\begin{tabular}{|c|c|c|c|c|c|c|c|c|}
\hline \multirow{2}{*}{$\begin{array}{l}\text { Location } \\
\text { in Figure } 2\end{array}$} & \multicolumn{4}{|c|}{ Case 2} & \multicolumn{4}{|c|}{ Case 3} \\
\hline & $\mathrm{PGA} /\left(\mathrm{m} \cdot \mathrm{s}^{-2}\right)$ & $\beta$ & $\mathrm{PGD} / \mathrm{cm}$ & $D_{\mathrm{r}, \max } / \mathrm{cm}$ & $\mathrm{PGA} /\left(\mathrm{m} \cdot \mathrm{s}^{-2}\right)$ & $\beta$ & $\mathrm{PGD} / \mathrm{cm}$ & $D_{\mathrm{r}, \text { max }} / \mathrm{cm}$ \\
\hline (1) & 3.86 & 1.93 & 32.10 & 4.79 & 3.94 & 1.97 & 33.20 & 8.50 \\
\hline (2) & 3.20 & 1.61 & 30.62 & 3.31 & 3.49 & 1.74 & 31.89 & 6.62 \\
\hline (3) & 2.83 & 1.42 & 27.35 & 0.00 & 3.26 & 1.63 & 28.16 & 0.00 \\
\hline (4) & 2.29 & 1.15 & 29.15 & 1.81 & 1.72 & 0.86 & 28.08 & 15.27 \\
\hline (5) & 3.01 & 1.51 & 34.10 & 6.77 & 2.24 & 1.12 & 32.97 & 25.84 \\
\hline (6) & 4.82 & 2.41 & 35.37 & 8.07 & 2.72 & 1.36 & 34.40 & 28.73 \\
\hline
\end{tabular}

Note: PGA stands for peak ground acceleration and PGD for peak ground displacement; $D_{\mathrm{r}, \text { max }}$ denotes the maximum displacements relative to point (3); $\beta$ denotes the acceleration amplification coefficient. All these are the same in Tables 3 and 4.

Table 3 Ground motions under San Fernando wave

\begin{tabular}{|c|c|c|c|c|c|c|c|c|}
\hline \multirow{2}{*}{$\begin{array}{l}\text { Location } \\
\text { in Figure } 2\end{array}$} & \multicolumn{4}{|c|}{ Case 2} & \multicolumn{4}{|c|}{ Case 3} \\
\hline & $\mathrm{PGA} /\left(\mathrm{m} \cdot \mathrm{s}^{-2}\right)$ & $\beta$ & $\mathrm{PGD} / \mathrm{cm}$ & $D_{\mathrm{r}, \max } / \mathrm{cm}$ & $\mathrm{PGA} /\left(\mathrm{m} \cdot \mathrm{s}^{-2}\right)$ & $\beta$ & $\mathrm{PGD} / \mathrm{cm}$ & $D_{\mathrm{r}, \max } / \mathrm{cm}$ \\
\hline (1) & 4.55 & 2.28 & 21.14 & 5.33 & 5.44 & 2.72 & 13.98 & 3.64 \\
\hline (2) & 3.48 & 1.74 & 19.51 & 3.67 & 4.52 & 2.26 & 13.34 & 2.87 \\
\hline (3) & 3.22 & 1.61 & 19.86 & 0.00 & 3.26 & 1.63 & 11.14 & 0.00 \\
\hline (4) & 2.83 & 1.42 & 20.33 & 1.55 & 1.53 & 0.76 & 10.68 & 5.03 \\
\hline (5) & 3.87 & 1.94 & 21.40 & 5.59 & 2.16 & 1.08 & 12.82 & 8.07 \\
\hline (6) & 4.52 & 2.26 & 22.50 & 6.71 & 3.16 & 1.58 & 13.61 & 8.78 \\
\hline
\end{tabular}

Table 4 Ground motions under Parkfield wave

\begin{tabular}{|c|c|c|c|c|c|c|c|c|}
\hline \multirow{2}{*}{$\begin{array}{l}\text { Location } \\
\text { in Figure } 2\end{array}$} & \multicolumn{4}{|c|}{ Case 2} & \multicolumn{4}{|c|}{ Case 3} \\
\hline & $\mathrm{PGA} /\left(\mathrm{m} \cdot \mathrm{s}^{-2}\right)$ & $\beta$ & $\mathrm{PGD} / \mathrm{cm}$ & $D_{\mathrm{r}, \max } / \mathrm{cm}$ & $\mathrm{PGA} /\left(\mathrm{m} \cdot \mathrm{s}^{-2}\right)$ & $\beta$ & $\mathrm{PGD} / \mathrm{cm}$ & $D_{\mathrm{r}, \max } / \mathrm{cm}$ \\
\hline (1) & 4.35 & 2.18 & 11.69 & 2.07 & 4.91 & 2.45 & 22.25 & 4.72 \\
\hline (2) & 2.79 & 1.40 & 11.21 & 1.44 & 4.80 & 2.40 & 21.53 & 3.81 \\
\hline (3) & 3.67 & 1.84 & 10.75 & 0.00 & 3.77 & 1.89 & 18.63 & 0.00 \\
\hline (4) & 2.99 & 1.50 & 11.42 & 0.84 & 1.96 & 0.98 & 16.82 & 10.17 \\
\hline (5) & 2.71 & 1.36 & 12.50 & 2.89 & 1.94 & 0.97 & 18.02 & 18.37 \\
\hline (6) & 4.75 & 2.37 & 13.07 & 3.43 & 2.83 & 1.42 & 19.13 & 20.54 \\
\hline
\end{tabular}

of the canyon, on the whole. It can also be seen that the incident wave angle has an important effect on the peak ground acceleration (Figure 5). In the case 3, the observation points on the left slope of the canyon have bigger peak ground acceleration than those on the opposite side. On the left slope of the canyon the peak ground acceleration amplification coefficients in the case 3 are larger than those in the case 2; on the contrary, on the right 
slope of the canyon the peak ground acceleration amplification coefficients in the case 3 are smaller than those in the case 2 .

The relative displacements of surface ground motions are greatly affected by the incident angle of waves.
The relative displacements in the case 3 are much larger than those in the case 2 . This phenomenon may be relevant to the amplifications of ground motions and the time delays caused by different wave passages.
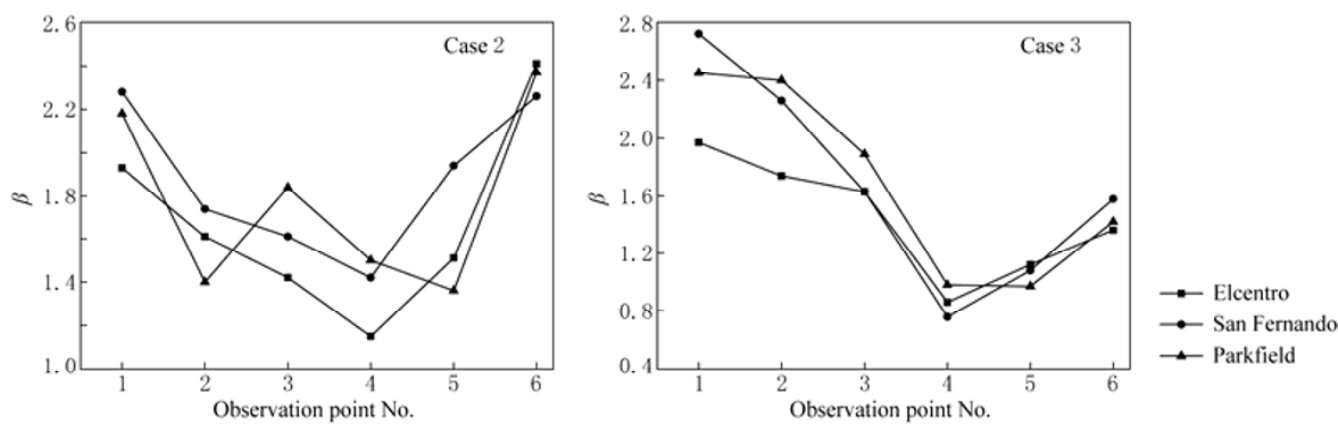

Figure 5 PGA amplification coefficients $(\beta)$ in two cases.

Canyon topographic effects are also strongly relevant to the source frequency content. In the case 2 , the coefficients $\beta$ under San Fernando wave are almost bigger than those under others. Otherwise, the amplification coefficients in the case 3 could hardly show any regularity likewise. We can see that the waves with different frequency content interact with small-scale topography to make the peak values amplified or diminished at different locations of the site. Furthermore, Figure 6 indicates that, compared with the case 2, case 3 produces obviously bigger amplification coefficient values on the canyon slope perpendicular to the incident direction and

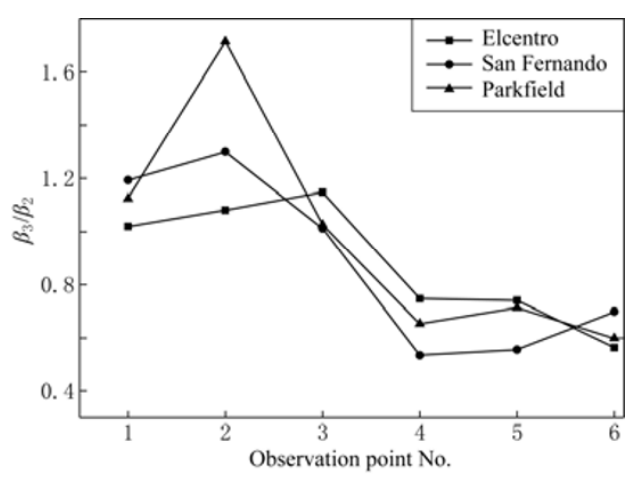

Figure 6 Comparison of PGA amplification coefficients $(\beta)$ for two cases, where $\beta_{3} / \beta_{2}$ denotes the ratio of $\beta$ in case 3 to that in case 2 . smaller coefficient values on the opposite side of the canyon.

Generally speaking, the topographical irregularities of the canyon have shown significant influences on the surface motions in terms of the source frequency content of incident waves and the incidence directions.

\section{Seismic response analysis of the bridge}

\subsection{Seismic excitations of bridge}

The ground motions of the six observation points (seen in Figure 2) under adjusted Elcentro SV incident wave are demonstrated in Figure 7, which are used as the seismic excitations of the bridge. The peak ground acceleration amplification coefficient spectra in two cases are shown in Figure 8; Figure 9 gives the displacement time histories of the six points relative to the observation point (3) at the canyon in two cases.

\subsection{Analytical methodology}

The large mass method (LMM) is used for multi-support seismic excitation analysis of extended structures (Leger et al, 1990). According to the LMM, a large mass element is set on the pier foundations of the structure, and then a force time history $P(t)$, which equals to $M_{0} \ddot{U}_{0}$ in value, is put on the large mass element. The formula of the LMM is described as follows:

$$
\left(\begin{array}{ccccc}
m_{11} & \cdots & m_{1 j} & \cdots & m_{1 n} \\
\vdots & \vdots & \vdots & \vdots & \vdots \\
m_{j 1} & \cdots & M_{0} & \cdots & m_{j n} \\
\vdots & \vdots & \vdots & \vdots & \vdots \\
m_{n 1} & \cdots & m_{n j} & \cdots & m_{n n}
\end{array}\right)\left\{\begin{array}{c}
\ddot{U}_{1} \\
\vdots \\
\ddot{U}_{j} \\
\vdots \\
\ddot{U}_{n}
\end{array}\right\}+\left(\begin{array}{ccccc}
c_{11} & \cdots & c_{1 j} & \cdots & c_{1 n} \\
\vdots & \vdots & \vdots & \vdots & \vdots \\
c_{j 1} & \cdots & c_{j j} & \cdots & c_{j n} \\
\vdots & \vdots & \vdots & \vdots & \vdots \\
c_{n 1} & \cdots & c_{n j} & \cdots & c_{n n}
\end{array}\right)\left\{\begin{array}{c}
\ddot{U}_{1} \\
\vdots \\
\ddot{U}_{j} \\
\vdots \\
\ddot{U}_{n}
\end{array}\right\}+\left\{\begin{array}{ccccc}
k_{11} & \cdots & k_{1 j} & \cdots & k_{1 n} \\
\vdots & \vdots & \vdots & \vdots & \vdots \\
k_{j 1} & \cdots & k_{j j} & \cdots & k_{j n} \\
\vdots & \vdots & \vdots & \vdots & \vdots \\
k_{n 1} & \cdots & k_{n j} & \cdots & k_{n n}
\end{array}\right)\left\{\begin{array}{c}
U_{1} \\
\vdots \\
U_{j} \\
\vdots \\
U_{n}
\end{array}\right\}=\left\{\begin{array}{c}
0 \\
\vdots \\
\left.M_{0} \ddot{U}_{0}\right\} \\
\vdots \\
0
\end{array}\right\}
$$



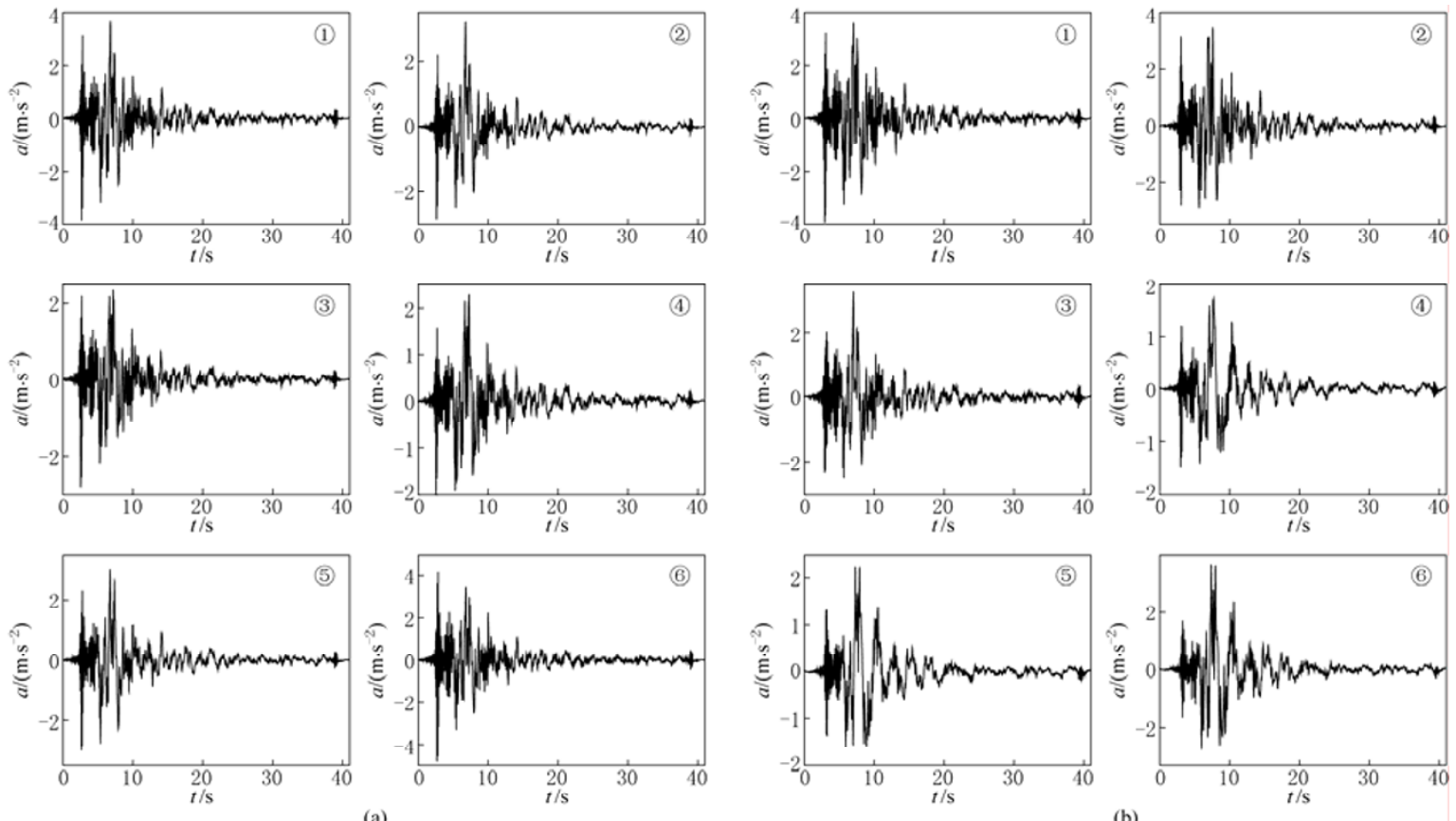

Figure 7 Seismic excitations under Elcentro SV incident wave for the six observation points (1), (2), ,.., (6) in Figure 2) in case 2 (a) and case $3(b)$
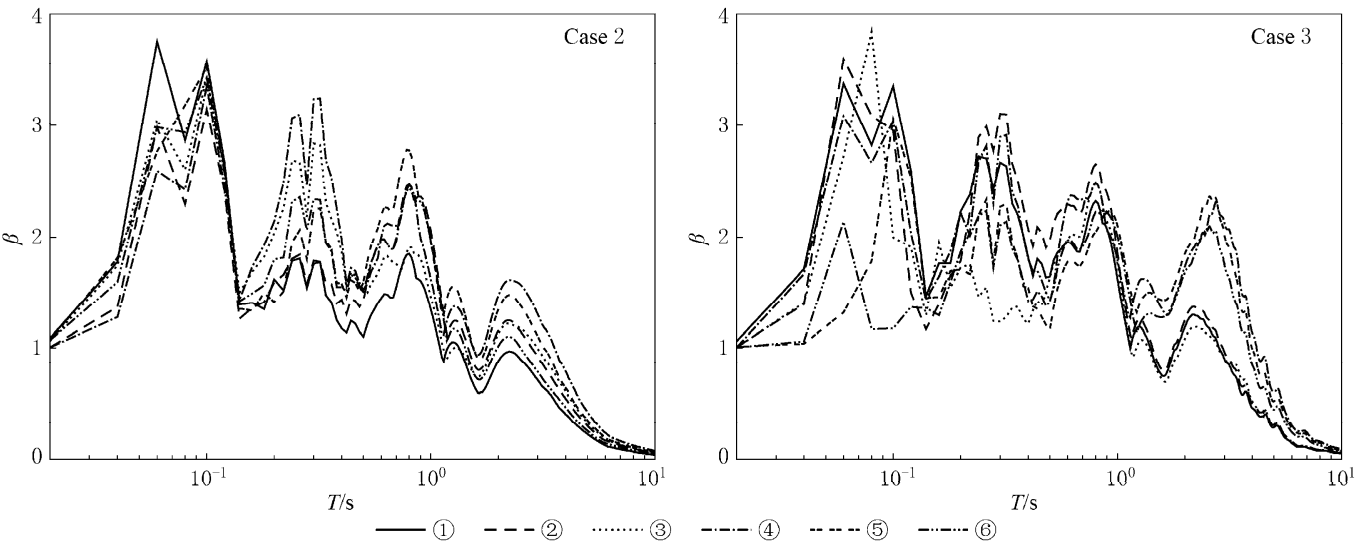

Figure 8 PGA amplification coefficient $(\beta)$ spectra of the six observation points (1), (2), , , (6) in Figure 2) in the two cases.
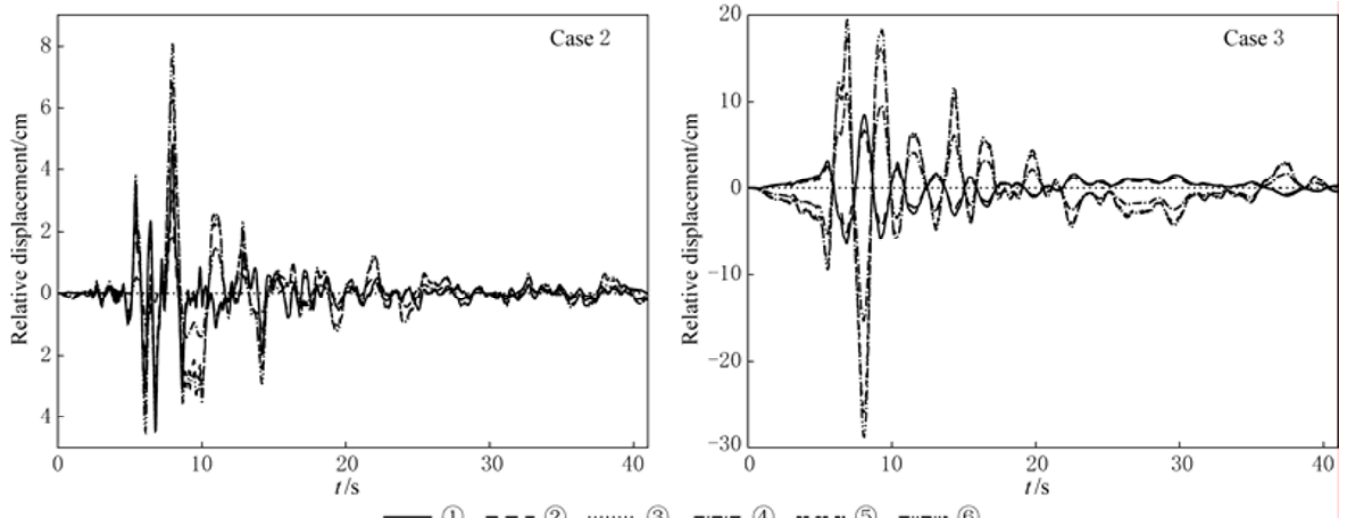

Figure 9 Relative displacement time histories of six observation points (1), (2), ,., (6) in Figure 2) relative to point (3) in two cases. 
where, $M_{0}$ is a mass element with a very big value as $10^{6}$ times large as the total mass of structure; $\ddot{U}_{0}$ denotes the ground motions at the pier foundations. When lumped mass matrix is used, $m_{i, j}(i \neq j)$ equals to zero. And the $j$ th row of formula (1) can be written as

$$
\ddot{U}_{j}+\sum_{i=1}^{n} \frac{c_{j i}}{M_{0}} \dot{U}_{i}+\sum_{i=1}^{n} \frac{k_{j i}}{M_{0}} U_{i}=\ddot{U}_{0} .
$$

For the large value of $M_{0}$, formula (2) can be approximately simplified as

$$
\ddot{U}_{j} \approx \ddot{U}_{0} .
$$

It can be seen that the LMM is an approximate solution for multi-support excitations analysis of large structures. It has been validated that the LMM is applicable to uniform excitation analysis. So, the LMM have been applied to multi-support seismic excitation analysis of many structures.

However, this method is unsuitable for the analysis with the Rayleigh damping assumption, because the large value of $M_{0}$ on the base would lead to a large additional damping force, which may bring inaccurate displacement time histories of pier foundations. As is well known, in multi-support seismic excitation analysis, both the pseudo-static displacements and the dynamic displacements depend on the displacements of pier foundations, therefore inaccurate displacements of pier foundations lead to inaccurate results.

We have presented an improved LMM to deal with the inapplicability of the traditional LMM (Zhou et al, 2010). When Rayleigh damping is used, the parameter $c_{j j}=\alpha M_{0}+\beta k_{j j}$, and the formula (2) can be simplified as

$$
\ddot{U}_{j}+\alpha \dot{U}_{j} \approx \ddot{U}_{0} .
$$

Compared with equation (3), the item $\alpha \dot{U}_{j}$ causes $\ddot{U}_{j} \neq \ddot{U}_{0}$. In order to satisfy $\ddot{U}_{j}=\ddot{U}_{0}$, let $\ddot{U}_{j, \text { new }}$ represents the real input excitation, then equation (4) can be rewritten as

$$
\ddot{U}_{j, \text { new }}=\ddot{U}_{0}+\alpha \dot{U}_{0} \text {. }
$$

This means the real excitations should be modified as equation (5), in which $\alpha \dot{U}_{0}$ is used to counteract the additional damping force on the pier foundations. It has been validated in our earlier study that the improved LMM is in good agreement with the theoretical method, and the errors can be decreased to $1 \%-2 \%$ (Zhou et al, 2010).

\subsection{Finite element model of rigid frame bridge}

The finite element model of the bridge is formed, which consists of 680 elements. The piers and beams are simulated with spatial beam element and the bearings are simulated using springs with the precondition of no pounding phenomena among superstructures. The soilstructure interaction is not taken into account. Three cases are assumed as: case 1, uniform excitation with the peak ground acceleration of $4 \mathrm{~m} / \mathrm{s}^{2}$, which denotes the case that no canyon topography effects are considered; the case 2 and the case 3 are defined as the mentioned above. And all the excitations are along the longitudinal direction. The damping coefficient $\alpha$ is 0.11 , and $\beta$ is 0.009 . The modal information of the bridge is demonstrated in Figure 10.

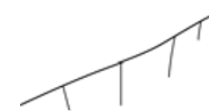

(a)

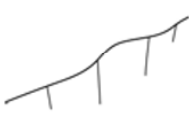

(e)

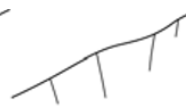

(b)

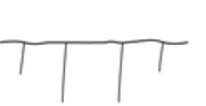

(c)

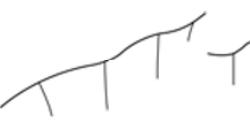

(f)

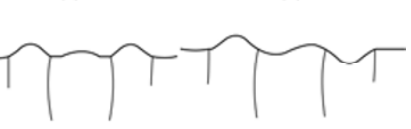

(g)

(h)

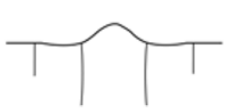

Figure 10 The mode shapes under different vibration pe-

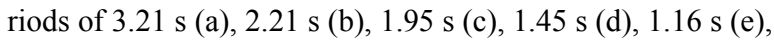
$0.90 \mathrm{~s}(\mathrm{f}), 0.82 \mathrm{~s}(\mathrm{~g})$ and $0.81 \mathrm{~s}(\mathrm{~h})$.

\subsection{Parameters analysis}

Based on the improved LMM, the seismic response analysis of the bridge has been carried out using direct integration method. Figure 11 provides partial results of the bridge in the three cases. In Tables 5 and 6 and Fig-

\begin{tabular}{|c|c|c|c|c|c|c|c|c|c|}
\hline \multirow{2}{*}{$\begin{array}{l}\text { Location in } \\
\text { Figure } 2\end{array}$} & \multicolumn{3}{|c|}{ Case 1} & \multicolumn{3}{|c|}{ Case 2} & \multicolumn{3}{|c|}{ Case 3} \\
\hline & $N / \mathrm{MN}$ & $F_{y} / \mathrm{MN}$ & $M_{z} /(\mathrm{MN} \cdot \mathrm{m})$ & $N / \mathrm{MN}$ & $F_{y} / \mathrm{MN}$ & $M_{z} /(\mathrm{MN} \cdot \mathrm{m})$ & $N / \mathrm{MN}$ & $F_{y} / \mathrm{MN}$ & $M_{z} /(\mathrm{MN} \cdot \mathrm{m})$ \\
\hline$S_{1}$ & 38.95 & 5.51 & 481.28 & 39.64 & 6.95 & 529.35 & 66.29 & 7.69 & 636.36 \\
\hline$S_{2}$ & 9.63 & 0.97 & 33.84 & 14.84 & 2.27 & 61.21 & 63.79 & 1.19 & 44.71 \\
\hline$C_{0}$ & 6.28 & 0.45 & 0.66 & 7.85 & 0.8 & 1.43 & 58.52 & 1.29 & 2.09 \\
\hline$S_{3}$ & 21.71 & 0.99 & 36.72 & 17.30 & 9.42 & 491.79 & 47.39 & 6.39 & 349.72 \\
\hline$S_{4}$ & 49.45 & 5.82 & 520.1 & 15.03 & 6.98 & 682.2 & 10.28 & 7.01 & 597.75 \\
\hline
\end{tabular}
ure 12 , the comparison of seismic response at the key locations in the bridge is given.

Table 5 Results of frames

Note: $N$ stands for axial force and $F_{y}$ for peak shear force in $y$ direction, and $M_{z}$ denotes peak bending moment in $z$ direction. 
Table 6 Results of piers

\begin{tabular}{|c|c|c|c|c|c|c|c|}
\hline \multirow{2}{*}{ Pier } & \multirow{2}{*}{ Location } & \multicolumn{2}{|c|}{ Case 1} & \multicolumn{2}{|c|}{ Case 2} & \multicolumn{2}{|c|}{ Case 3} \\
\hline & & $F_{x} / \mathrm{MN}$ & $M_{z} /(\mathrm{MN} \cdot \mathrm{m})$ & $F_{x} / \mathrm{MN}$ & $M_{z} /(\mathrm{MN} \cdot \mathrm{m})$ & $F_{x} / \mathrm{MN}$ & $M_{z} /(\mathrm{MN} \cdot \mathrm{m})$ \\
\hline \multirow[t]{2}{*}{$P_{1}$} & Top & 55.64 & 1270.18 & 54.75 & 1250.12 & 71.93 & 1560.13 \\
\hline & Bottom & 65.34 & 2880.35 & 64.94 & 2790.23 & 73.48 & 3300.65 \\
\hline \multirow[t]{2}{*}{$P_{2}$} & Top & 4.90 & 561.38 & 3.26 & 542.51 & 7.95 & 646.09 \\
\hline & Bottom & 22.28 & 1180.76 & 22.45 & 1190.08 & 19.45 & 990.14 \\
\hline \multirow[t]{2}{*}{$P_{3}$} & Top & 4.63 & 591.23 & 2.55 & 503.71 & 5.98 & 361.35 \\
\hline & Bottom & 22.06 & 1160.12 & 22.66 & 1160.82 & 14.80 & 1200.25 \\
\hline \multirow[t]{2}{*}{$P_{4}$} & Top & 65.82 & 1360.08 & 55.43 & 1150.32 & 50.26 & 1000.78 \\
\hline & Bottom & 70.27 & 3140.02 & 63.99 & 2640.10 & 55.49 & 2220.35 \\
\hline
\end{tabular}

Note: $F_{x}$ stands for peak shear force in the $x$ direction and $M_{z}$ for peak moment in the $z$ direction.
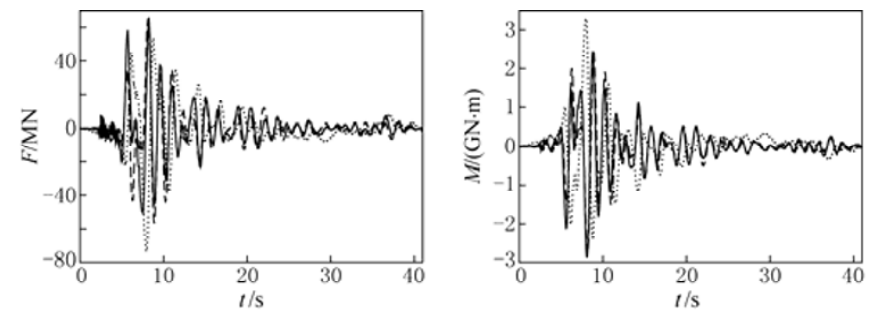

(a)
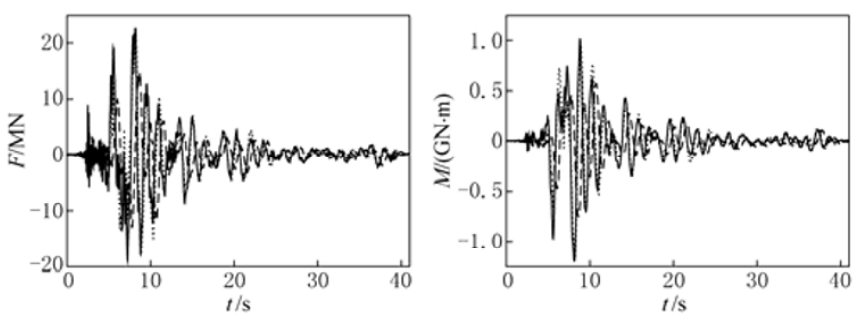

(c)
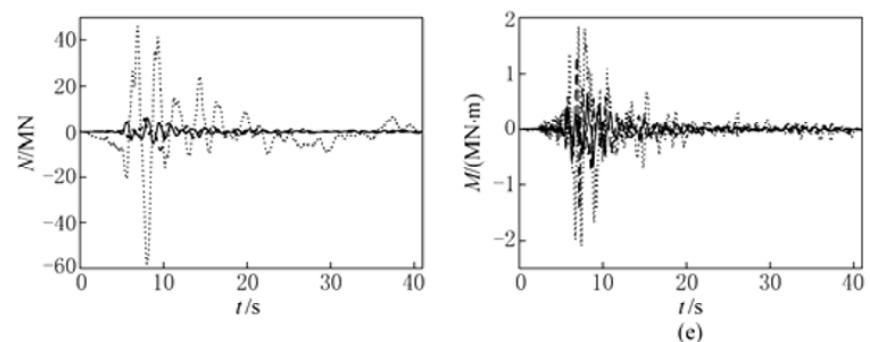
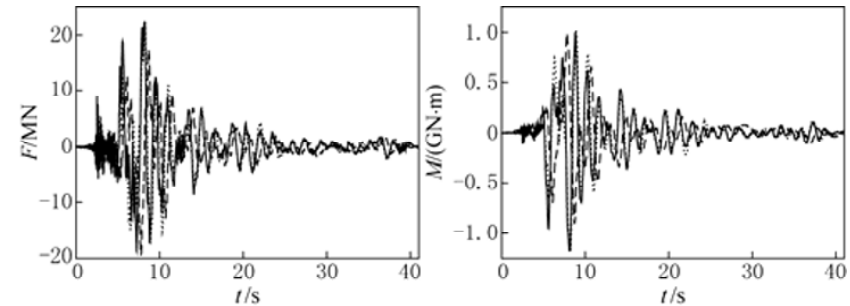

(b)
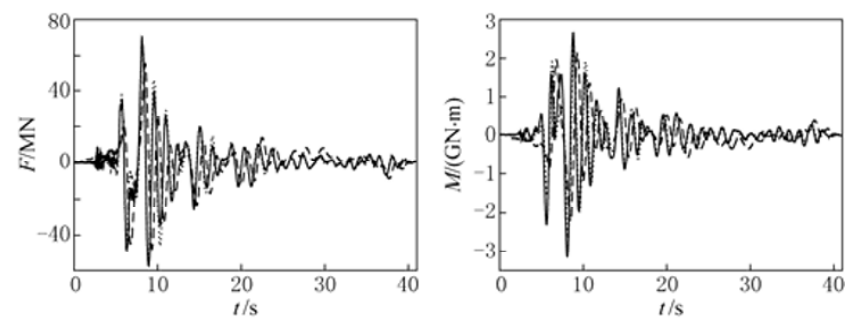

(d)

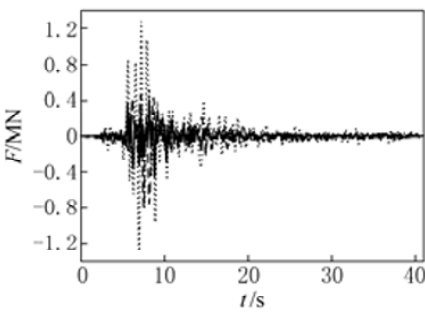

- Case 1

- - - Case 2

Figure 11 Seismic response of piers and frame. (a) Shear force $F$ and moment $M$ at the bottom of $P_{1}$; (b) Shear force and moment at the bottom of $P_{2}$; (c) Shear force and moment at the bottom of $P_{3}$; (d) Shear force and moment at the bottom of $P_{4}$; (e) Axial force $N$, moment $M$ and shear force $F$ at $C_{0}$.

In the three cases, the responses of the two low piers $\left(P_{1}\right.$ and $\left.P_{4}\right)$ have been more severe than that of the high piers $\left(P_{2}\right.$ and $\left.P_{3}\right)$. The shear force and moment of lower piers are both much larger than that of the high piers. This is because the lower piers have a larger bending rigidity.

The non-uniform excitations caused by the canyon topography show important influences on the structure. Generally speaking, the response in the cases 2 and 3 is bigger than that in the case 1. Especially in the case 3, the non-uniform excitation brings both the piers and frame severe response. This is because that: (1) the spectra of the excitations are quite different in the two cases, and (2) the relative displacement of support excitations in the case 3 is much larger than that in the case 2 . The relative displacement is relevant to the inner force of the structure. The site effects and incidence direction of the waves have an obvious influence on the rigid frame bridge. The uniform excitations could not bring the critical responses to structures. All these results indicate that the canyon topography effects on structures should be taken into consideration in aseismic design. 

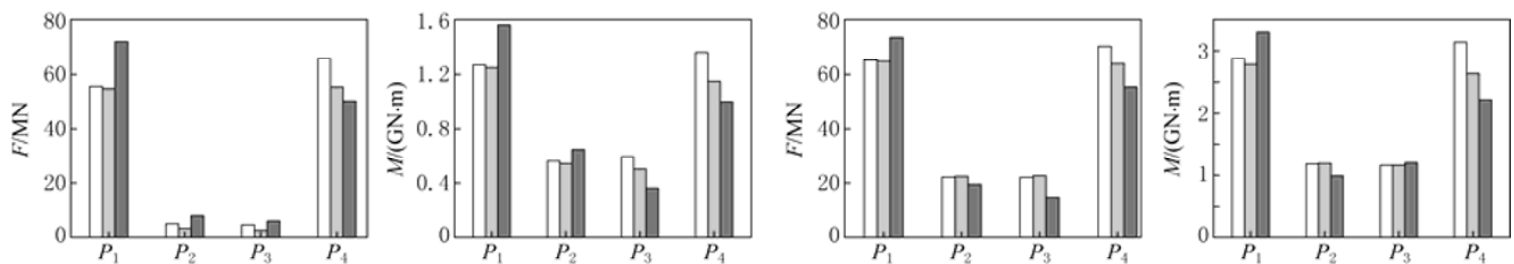

(a)
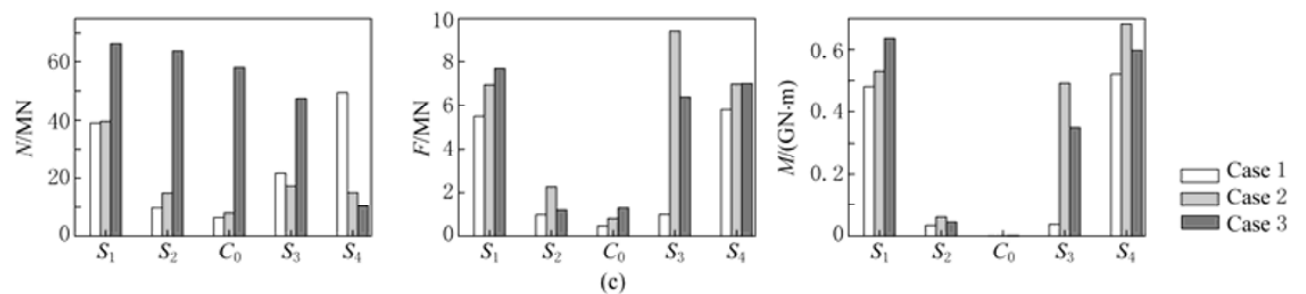

Figure 12 Peak responses of bridge in the three cases. (a) Peak shear force $(F)$ and peak moment $(M)$ at the top of four piers $P_{1}, P_{2}, P_{3}$ and $P_{4}$; (b) Peak shear force and peak moment at the bottom of four piers; (c) Peak axial force $(N)$, peak shear force and peak moment on the points $S_{1}, S_{2}, C_{0}, S_{3}$, and $S_{4}$ (seen in Figure 2).

\section{Conclusions}

Based on the two-dimensional site model, seismic analysis of the canyon is carried out under SV waves using the assumptions of vertical incidence and oblique incidence. With the improved LMM, the seismic response of a rigid frame bridge considering the canyon topography effects was analyzed herein. The conclusions can be drawn as follows.

1) The improved LMM is applicable to multisupport seismic excitation analysis of large structures with Rayleigh damping assumption.

2) The amplification coefficients of peak ground accelerations are affected obviously by the incident waves. The peak ground acceleration values of canyon topography differ significantly even under incident waves with the same peak ground acceleration, which indicates the spectra characteristics may be important factors that affect the ground motions.

3) The distribution of ground motions is affected by small-scale canyon topographic features and the incidence angle of the waves. In the case of vertical incident $\mathrm{SV}$ waves, the peak ground accelerations increase greatly at the upper corners of canyon; whereas the peak ground accelerations decrease at the bottom corners of canyon. In the case of oblique incident SV waves, the shaking of the slope perpendicular to the incidence direction is much more severe. However on the opposite side, the peak ground acceleration values decrease.

4) The relative displacements of ground motions mainly depend on the incident direction of SV waves.
Generally, the relative displacement increases obviously under oblique incident wave, compared with that under vertical incident wave.

5) Low piers undergo severe response under longitudinal excitations because of its bigger lateral stiffness. So the low piers should be attached much more attention.

6) The directions of input ground motion have distinct influences on response of rigid frame bridges. Generally speaking, the canyon topography effect under oblique incident waves brings more severe responses than that under uniform excitations. Canyon topography effect should be regarded as an important factor considered in bridge design.

7) The total response consists of pseudo-static response and dynamic response, which could be resonant or muffled. So, the complexity of the structural seismic response under multi-support excitations are derived from the idiographic course of the two kinds of responses mentioned above.

Acknowledgements This study is jointly supported by National Natural Science Foundation of China (No. 50708100), National Science and Technology Support Project of China (No. 2006BAC13B02) and partially by Basic Research Program of Institute of Mechanics Engineering, China Earthquake Administration (No. 2007B02).

\section{References}

Akira O and Kasaburo H (1983). Effect of topography and subsurface inhomogeneities on seismic SV waves. Earthq Eng Struct Dynam 11(4): 
441-462.

Che W and Luo Q F (2008). Seismic wave propagation in complex topography. Chinese J Geotech Eng 30(9): 1333-1 337 (in Chinese with English abstract).

Hu Y X and Sun P S (1981). Site effect on seismic disaster and ground motion. Earthq Eng Eng Vib 1: 41-54 (in Chinese with English abstract).

Huang H C and Chiu H C (1995). The effect of canyon topography on strong ground motion at Feitsui dam site: Quantitative results. Earthq Eng Struct Dynam 24(7): 977-990.

Kiureghan (1992). Response spectrum method for multi-support seismic excitations. Earthq Eng Struct Dynam 21(8): 713-740.

Lee S J, Chan Y C, Komatitsch D, Huang B S and Tromp J (2009). Effects of realistic surface topography on seismic ground motion in the Yangminshan region of Taiwan based upon the spectral-element method and lidar DTM. Bull Seism Soc Amer 99(2A): 681-693.

Leger P, Ide I M and Paultre P (1990). Multiple support seismic analysis of large structures. Computers \& Structures 36: 153-158.

Li W H and Zhao C G (2004). Scattering of plane SV waves by circular-arc alluvial canyons with saturated soil deposits. Chinese J Geophys 47(5): 911-919 (in Chinese with English abstract).
Liao Z P (1996). Introduction to Wave Motion Theories for Engineering. Science Press, Beijing, 156-163 (in Chinese).

Sextos A G, Kappos A J and Pitilakis K D (2003). Inelastic dynamic analysis of $\mathrm{RC}$ bridges accounting for spatial variability of ground motion, site effects and soil-structure interaction phenomena. Part 2: Parametric study. Earthq Eng Struct Dynam 32: 629-652.

Zhao C B and Valliappan S (1993). Seismic wave scattering effects under different canyon topographic and geological conditions. Soil Dynam Earthq Eng 12(3): 129-143.

Zhou G L (2004). Research on Seismic Response of Continues Rigid Frame Bridges with High Piers and Long Span. Master Dissertation, Institute of Geophysics, China Earthquake Administration, Beijing, 10-20 (in Chinese with English abstract).

Zhou G L, Li X J and Liu B D (2010). Error analysis and improvements of Large Mass Method used in multi-support seismic excitation analysis. Eng Mech in press (in Chinese with English abstract). 